\title{
Sistem Informasi Geografis Destinasi Ngumpul Asik "NguSik" Berbasis Platform Android
}

\author{
I Made Budi Setiawan, Dwi Putra Githa, I Made Sunia Raharja \\ Program Studi Teknologi Informasi, Fakultas Teknik, Universitas Udayana, Bukit \\ Jimbaran, Bali, Indonesia, telp. (0361)701806 \\ e-mail: budiclamp@gmail,com,dwiputragitha@unud.ac.id,sunia.raharia@gmail.com
}

\begin{abstract}
Abstrak
Mobile Phone saat ini tidak hanya digunakan untuk sarana komunikasi biasa, melainkan digunakan untuk mencari lokasi-lokasi yang diinginkan, salah satunya destinasi ngumpul atau sering disebut dengan istilah "nongkrong" yang berasal dari kata dasar kumpul. Kurangnya informasi menimbulkan banyaknya masyarakat yang belum mengetahui informasi rinci dari destinasi ngumpul yang ada. Minimnya informasi rinci dari hasil yang diberikan oleh sistem yang ada mendasari pengembangan sistem informasi geografis destinasi ngumpul asik. Sistem dirancang berbasis Android dengan bantuan Google Maps API, sehingga dapat mempermudah dalam mencari informasi secara rinci terhadap suatu destinasi kumpul tanpa harus berkunjung sebelumnya. Informasi rinci yang ditampilkan berupa rute lokasi, informasi menu, informasi harga, dan informasi fasilitas. Pengguna juga dapat melakukan berbagi informasi posisi terhadap teman pengguna melalui fitur check in yang disediakan.
\end{abstract}

Kata Kunci : Destinasi Ngumpul, Sistem Informasi Geografis, Google Maps API, Android

\begin{abstract}
At this time, mobile phones are not only used for ordinary communication facilities, but are used to search for desired locations, one of that locations is gather location or often referred as hang out which comes from the base word gathered. The lack of information about that make many people don't know the detailed information of the existing hang out destinations. The lack of detailed information on the results provided by the existing system which became the main purpose of geographic information system of hang out destinations develop for. The system is designed based on Android with Google Maps API, so that it can be easier to find detailed information about hang out destinations without having visit the locations before. Detailed information that displayed are location routes, menu information, price information, and facility information. User can also share position information to their friends by check in feature that provided.
\end{abstract}

Keywords : Hang Out Destination, Geographic Information System, Google Maps API, Android

\section{Pendahuluan}

Mobile phone berkembang cukup pesat. Perangkat mobile phone pada awalnya digunakan sebagai alat komunikasi suara dan pengiriman pesan, namun sekarang digunakan untuk berbagai kebutuhan. Mobile phone pada setiap kesempatan dan di berbagai tempat digunakan untuk berbagai hal, sehingga menjadi suatu kebutuhan yang tak dapat dipisahkan. Kegunaan dari mobile phone seperti sarana berbagi informasi, sarana media sosial, ataupun sebagai media pembantu dalam menemukan suatu lokasi. Lokasi dapat ditemukan menggunakan mobile phone dikarenakan peta yang digunakan pada perangkat mobile phone bersifat dinamis. Lokasi yang dapat ditemukan menggunakan mobile phone yaitu destinasi ngumpul atau nongkrong. Ngumpul berasal dari kata kumpul. Ngumpul merupakan aktivitas yang telah menjadi gaya hidup dalam rangka mengisi waktu kosong dengan cara berbincang, berkumpul, ataupun sembari menikmati suatu hidangan yang memiliki potensi besar dalam mengurangi stres dan dapat meningkatkan kreativitas di dalam berpikir dan berkarya [1]. Ngumpul tidak hanya dilakukan di rumah saja, melainkan dapat dilakukan di lokasi yang 
menyediakan sarana dan prasarana yang ada. Kurangnya informasi rinci terhadap destinasi ngumpul, dimana ngumpul tersebut telah menjadi gaya hidup, serta kebutuhan dalam penggunaan mobile phone yang tinggi menjadi dasar dalam pengembangan sistem informasi geografis destinasi ngumpul asik. Sistem informasi geografis destinasi ngumpul yang dibangun diatas platform Android dengan bantuan Google Maps API diharapkan dapat memberikan informasi yang rinci terhadap destinasi ngumpul yang ada.

Penelitian sebelumnya yang diacu diantaranya, aplikasi sistem informasi geografis bengkel di kota Denpasar yang membahas tentang pemanfaatan teknologi smartphone untuk pelacakan lokasi [2], sistem informasi geografis public complaint yang membahas tentang LBS untuk keakuratan koordinat [3], implementasi global positioning system (GPS) pada sistem informasi kereta api untuk wilayah jabodetabek terkait layanan GPS [4], sistem informasi geografis pemetaan jalan desa berbasis web yang membahas tentang penggunaan MySQL sebagai penyimpanan data [5], FinDoctor-Android clinic geographical information system using firebase and google maps API membahas mengenai penggunaan Firebase untuk memberi fitur notifikasi pada sistem [6], serta rural road mapping geographic information system using mobile Android membahas mengenai penggunaan teknologi mobile GPS dalam mempermudah pengumpulan data dan lebih mudah dalam mengakses informasi peta [7]. Penelitian aplikasi sistem informasi geografis bengkel di kota Denpasar berbasis Android membahas mengenai teknologi smartphone untuk pelacakan lokasi. Kemajuan teknologi berdampak pada hampir setiap orang memiliki perangkat smartphone untuk menunjang berbagai aktivitas seperti mengakses internet, mempermudah pekerjaan, bermain game, dan pelacakan lokasi berdasarkan geografis dengan memanfaatkan Google Map Api. Penelitian mengenai sistem informasi geografis public complaint membahas mengenai LBS untuk keakuratan koordinat komplain publik. LBS merupakan kepanjangan dari Location Based Service, dimana dapat memberikan data akurat terhadap koordinat dari pengguna, sehingga menghasilkan data yang real time. Penelitian tentang implementasi global positioning system (GPS) dan location based service (LSB) pada sistem informasi kereta api untuk wilayah jabodetabek membahas mengenai layanan GPS. Sistem GPS menggunakan sinyal satelit dalam menjalankan navigasi. Pengguna dapat menerima data berupa data longitude dan latitude yang digunakan dalam pencarian informasi seperti kecepatan, arah yang dituju, jalur, dan sebagainya dengan sistem ini. Penelitian mengenai sistem informasi geografis pemetaan jalan desa berbasis web yang membahas tentang penggunaan MySQL sebagai penyimpanan data. Sistem dirancang dengan menggunakan basis data MySQL agar dapat menangani penambahan, manipulasi, dan memberikan report dari data jalan desa yang memberikan informasi terkait jalan desa tersebut, seperti nama jalan, panjang jalan, kondisi dan jenis permukaan jalan yang ada di daerah Bali. Penelitian mengenai FinDoctor-Android clinic geographical information system using firebase and google maps API membahas mengenai penggunaan Firebase untuk memberi fitur notifikasi pada sistem. Sistem menggunakan Firebase yaitu Firebase real-time database yang dapat menangani data obrolan serta Firebase notification yang dapat digunakan dalam membuat notifikasi yang diterapkan pada sistem tersebut untuk ponsel pasien. Penelitian mengenai rural road mapping geographic information system using mobile Android membahas mengenai mobile GPS dalam mempermudah pengumpulan data dan lebih mudah dalam mengakses informasi peta. Teknologi GPS aktif smartphone, dapat dimanfaatkan dalam pengumpulan data jalan secara efisien karena peta yang bersifat dinamis serta lebih mudah dalam mengakses peta, karena dapat diakses pada perangkat mobile. GIS mobile pada sistem rural road mapping menggunakan teknologi GPS untuk mencari lokasi jalan desa.

Berdasarkan pada penelitian-penelitian sebelumnya, belum ada aplikasi yang memberikan informasi rinci terhadap destinasi ngumpul serta memiliki fitur check in dan chatting pada platform Android. Sistem dibangun diatas platform Android dikarenakan mudah dioperasikan dimanapun dan kapanpun pengguna berada [8] . Sistem diharapkan mempermudah pencarian destinasi-destinasi ngumpul, serta memberikan informasi yang mendetail terhadap destinasi ngumpul, baik berupa rute menuju lokasi ataupun fitur-fitur menarik seperti check in dan chatting yang dapat menambah informasi dan hubungan ke sesama penikmat ngumpul. 


\section{Metode Penelitian}

Metode yang digunakan dalam pengembangan sistem informasi geografis destinasi ngumpul asik "NguSik" berbasis platform Android adalah metode waterfall. Penggunaan metode ini dikarenakan pendekatan yang dilakukan pada sistem tersusun secara sistematis dan berurutan. Pengerjaan suatu sistem pada proses metode waterfall dilakukan secara berurutan. Tahap-tahap yang terdapat pada metode waterfall adalah analisis kebutuhan, pengumpulan data, perancangan sistem, implementasi sistem, pengujian sistem dan evaluasi, dan maintenance sistem.

\subsection{Gambaran Umum}

Sistem informasi geografis destinasi ngumpul asik "NguSik" berbasis platform Android merupakan sistem yang menyediakan informasi rinci dari destinasi ngumpul yang terdaftar. Sistem dibangun menggunakan konsep real time sehingga data yang diterima akurat serta dapat diakses kapanpun dan dimanapun. Sistem NguSik juga menyediakan beberapa fitur yang dapat menunjang komunikasi antar pengguna.

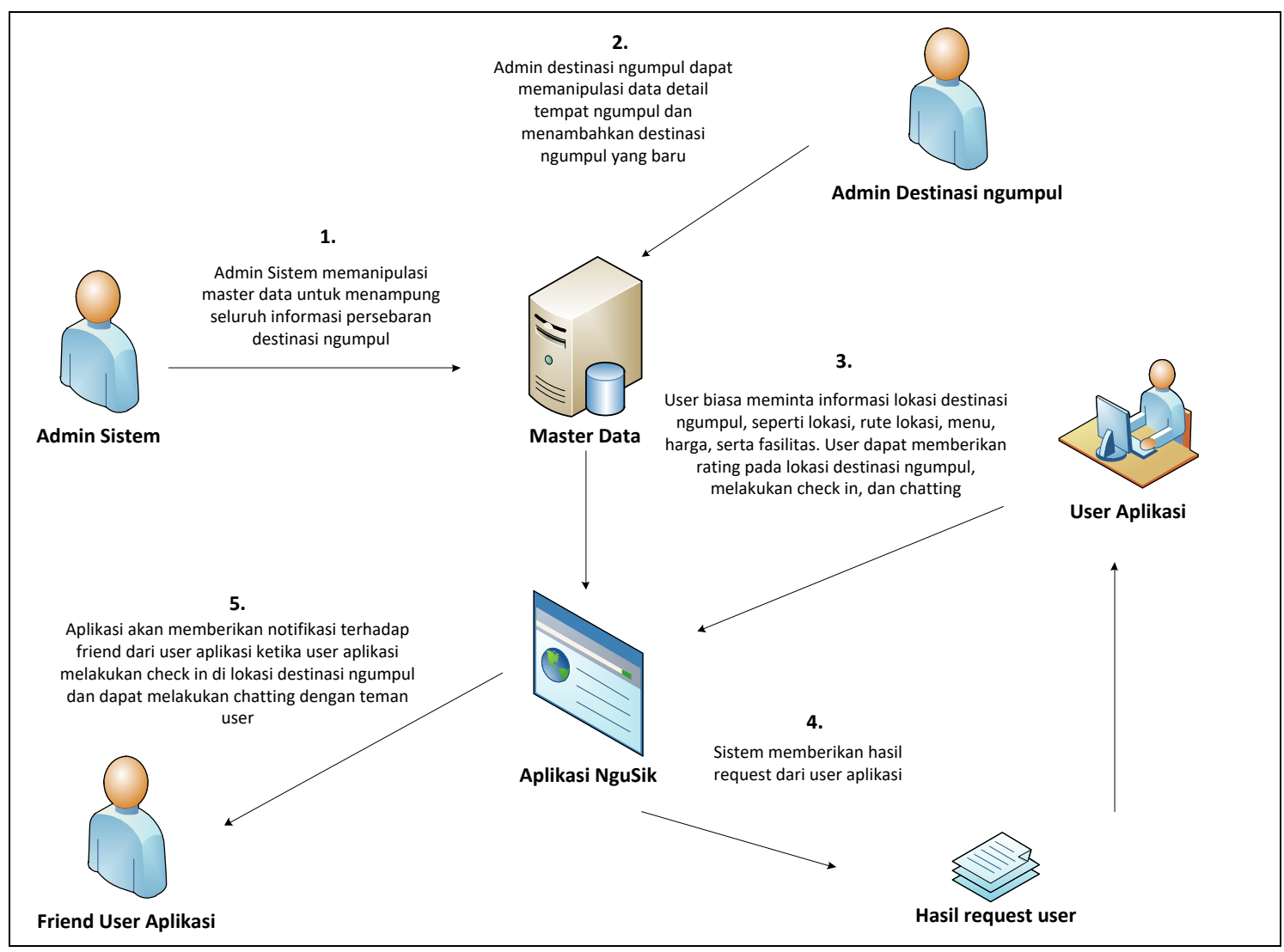

Gambar 1. Gambaran Umum Sistem

Gambaran umum sistem dapat dilihat seperti Gambar 1. Admin sistem dapat melakukan seluruh hal dalam sistem seperti memanipulasi data yang ada. Admin destinasi atau pemilik toko harus melakukan sign up terlebih dahulu agar terdaftar pada sistem dan dapat menambahkan destinasi serta memanipulasi data destinasinya namun dengan persetujuan admin sistem. Pengguna biasa dapat mengakses sistem dengan cara mendaftarkan diri terlebih dahulu, kemudian pengguna biasa dapat mengakses fitur-fitur yang ada pada sistem Android, seperti melihat destinasi yang ada, melihat informasi detail dari destinasi, maupun melakukan check in yang dapat mengirimkan notifikasi ke teman pengguna biasa tersebut. Sistem segera mengirimkan jawaban terhadap request yang diinginkan pengguna tersebut, ketika pengguna biasa melakukan request. 


\section{Kajian Pustaka}

\subsection{Ngumpul atau Nongkrong}

Ngumpul atau biasa disebut nongkrong merupakan suatu aktivitas yang menjadi suatu kebiasaan. Nongkrong biasanya dilakukan dalam rangka mengisi waktu kosong dengan cara berbincang, berkumpul, ataupun sembari menikmati suatu hidangan. Budaya nongkrong ini memiliki potensi yang besar dalam mengurangi stres dan dapat meningkatkan kreativitas di dalam berpikir dan berkarya [1].

\subsection{Sistem Informasi Geografis Berbasis Ponsel}

Sistem Informasi geografis berbasis ponsel merupakan gabungan teknologi sistem informasi geografis dan GPS, perangkat keras ponsel dan perangkat lunak, serta komunikasi wireless sebagai akses ke internet. Sistem geografis berbasis ponsel memberikan nilai yang tinggi dalam hal fleksibilitas, sehingga dapat memberikan pengguna hasil sesuai kebutuhan dengan sangat cepat. Sistem geografis basis ponsel memberikan akses kepada pengguna terhadap data dari segala tempat. Jaringan nirkabel, server, serta ponsel klien, merupakan komponen pembentuk sistem geografis basis ponsel [9].

\subsection{Android}

Android adalah sistem operasi berbasis Linux yang dasar pengembangan ditujukan ke perangkat mobile. Sistem Android pada awalnya dikembangkan oleh Android Inc, kemudian sistem Android dibeli oleh Google pada tahun 2005. Open Handset Alliance (OHA) dibentuk pada tahun 2007 dalam usaha mengambangkan Android. OHA merupakan pembiayaan bersama dari beberapa perusahaan, yaitu Marvell Technology Group, Intel, Broadcom Corporation, Motorola, Google, LG, Nvidia, Qualcomm, Samsung Electronics, Texas Instruments, HTC, Sprint Nextel, dan T-Mobile yang tujuannya adalah mengembangkan standar terbuka pada perangkat mobile [10].

\section{Hasil dan Pembahasan}

Hasil serta pembahasan menampilkan hasil tampilan serta pembahasan sistem informasi geografis destinasi ngumpul asik "NguSik" berbasis platform Android yang telah dibuat. Sistem terbagi ke dalam tiga tampilan. Tampilan yang terdapat pada sistem diantaranya tampilan di sisi sistem pengguna biasa, tampilan di sisi sistem admin destinasi, dan tampilan di sisi sistem admin sistem.

\subsubsection{Tampilan Sistem Pengguna Biasa}

Tampilan sistem pengguna biasa merupakan tampilan sistem yang digunakan oleh pengguna biasa pada platform Android. Tampilan pada sistem pengguna biasa terdiri dari tampilan halaman guest, tampilan halaman login dan sign up, tampilan halaman awal, tampilan detail destinasi, tampilan check in, dan tampilan chatting. Tampilan halaman guest berisi informasi persebaran destinasi yang telah terdaftar, seperti yang digambarkan pada Gambar 2. 


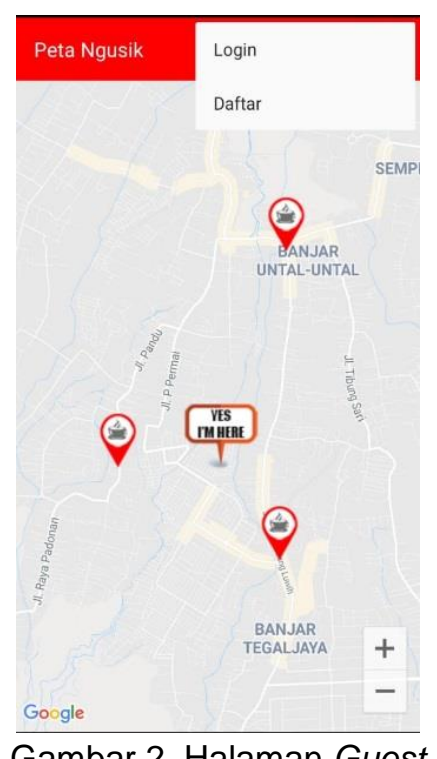

Pengguna biasa harus melakukan login agar dapat mengakses halaman utama dari sistem Android, pengguna biasa harus melakukan login. Bagi pengguna biasa yang belum memiliki akun harus melakukan registrasi pada halaman sign up seperti yang terlihat pada Gambar 3.

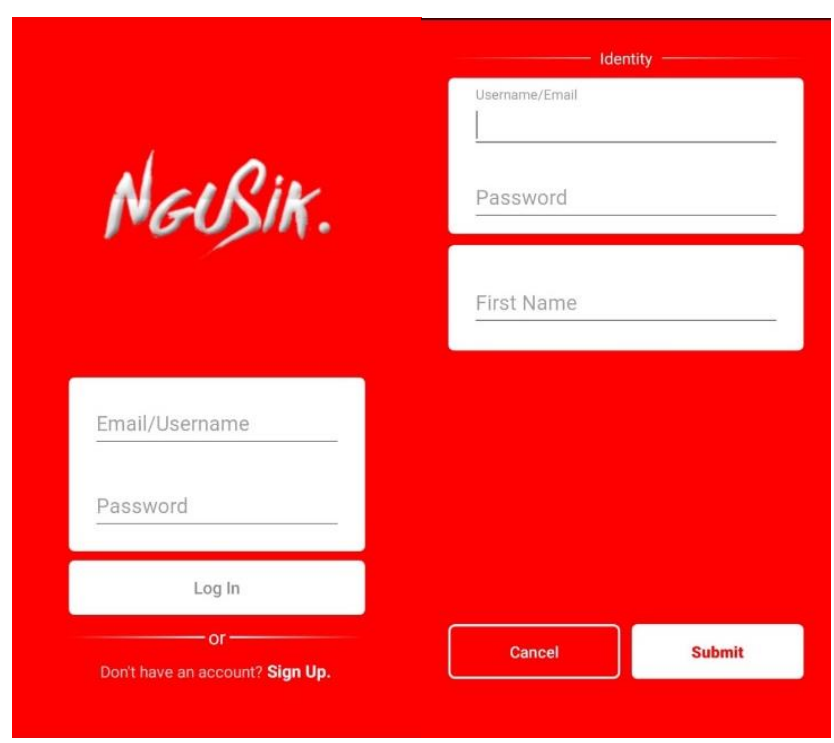

Gambar 3. Halaman Login dan Sign Up

Pengguna biasa yang telah melakukan login atau sign up dihadapkan dengan halaman utama. Tampilan halaman utama dapat dilihat seperti pada Gambar 4. 


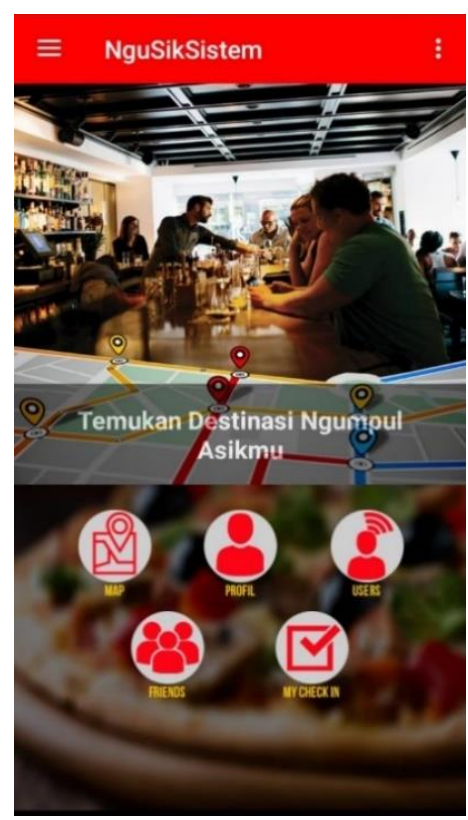

Gambar 4. Halaman Utama

Pengguna biasa yang sudah login dapat mengakses informasi detail dari destinasi yang terdaftar. Tampilan detail destinasi dapat dilihat seperti pada Gambar 5.

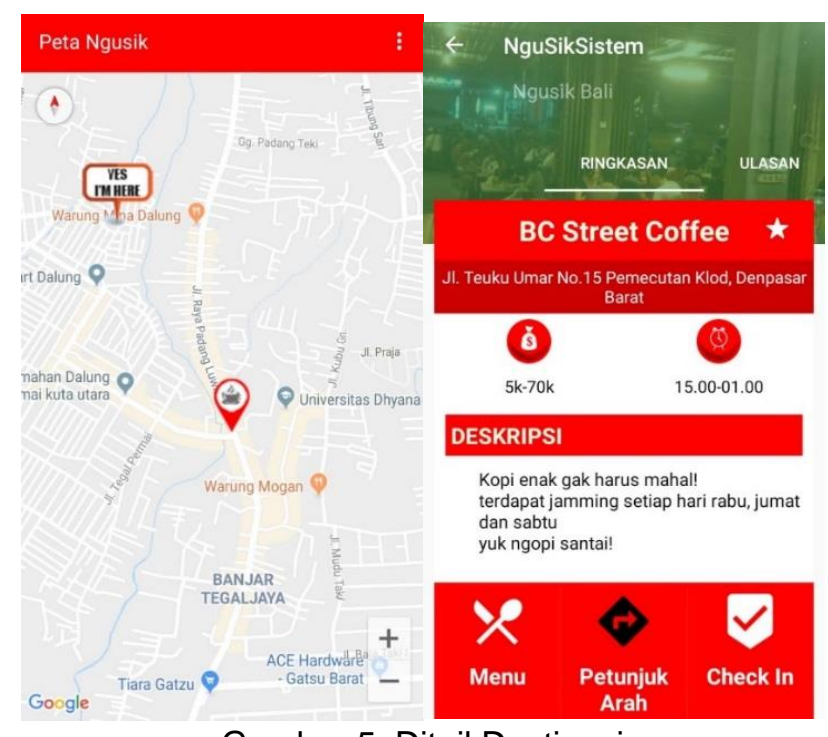

Gambar 5. Ditail Destinasi

Pengguna biasa yang telah melihat detail destinasi, ketika berada pada koordinat destinasi tersebut dapat melakukan check in. Tampilan check in dapat dilihat seperti pada Gambar 6. 


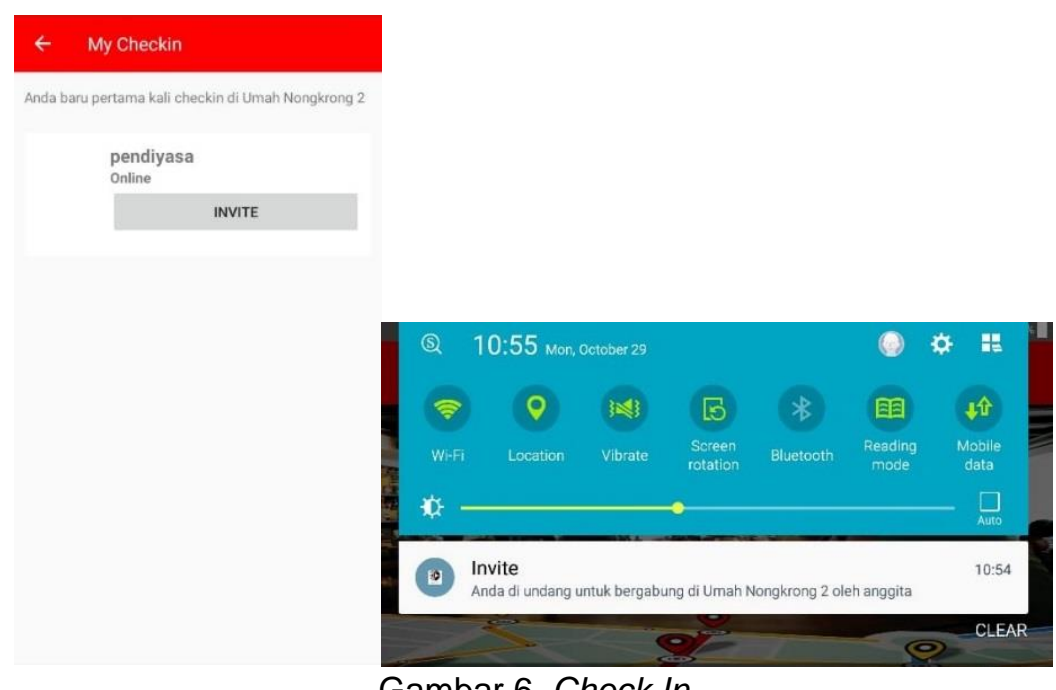

Pengguna yang telah melakukan hubungan pertemanan pada sistem dapat saling berkomunikasi dengan fitur chatting. Tampilan halaman chatting dapat dilihat seperti pada Gambar 7.

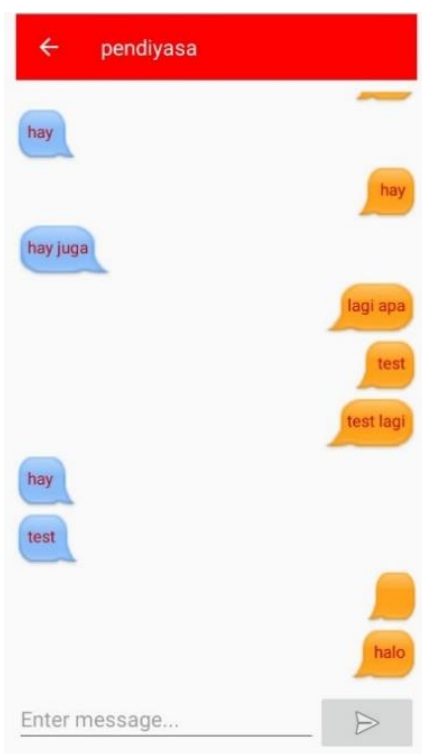

Gambar 7. Chatting

Pengguna biasa dapat melakukan chatting dengan teman pengguna biasa. Pengguna biasa harus melakukan hubungan pertemanan terlebih dahulu agar dapat melakukan chatting. Chatting dapat dilakukan ke teman pengguna biasa yang berada pada status online.

\subsubsection{Tampilan Sistem Admin Destinasi}

Tampilan sistem admin destinasi merupakan tampilan sistem yang digunakan oleh admin destinasi pada platform Web dan Android. Tampilan pada sistem admin destinasi terdiri dari tampilan halaman login dan sign up, tampilan halaman destinasi approved, tampilan halaman destinasi unapproved, dan tampilan tambah destinasi. Admin destinasi yang telah terdaftar dapat langsung melakukan login, sedangkan admin destinasi yang belum terdaftar harus melakukan sign up. Tampilan halaman login dan sign up dapat dilihat seperti pada Gambar 8. 

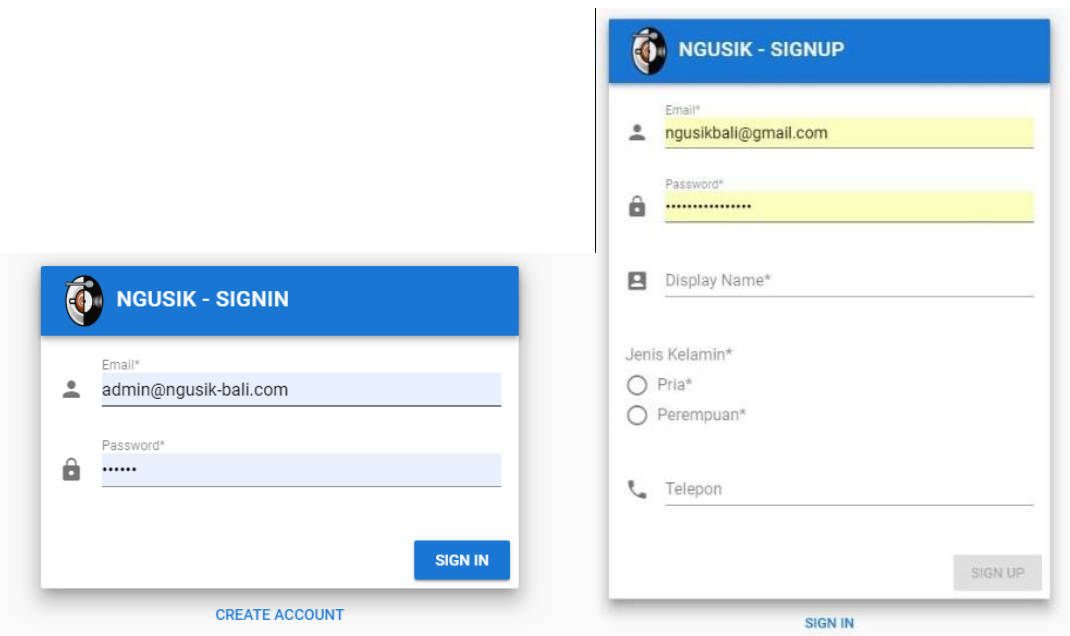

Gambar 8. Login dan Sign Up Admin Destinasi

Halaman admin destinasi memiliki menu destinasi approved dan destinasi unapproved. Tampilan halaman destinasi approved dapat dilihat seperti pada Gambar 9.

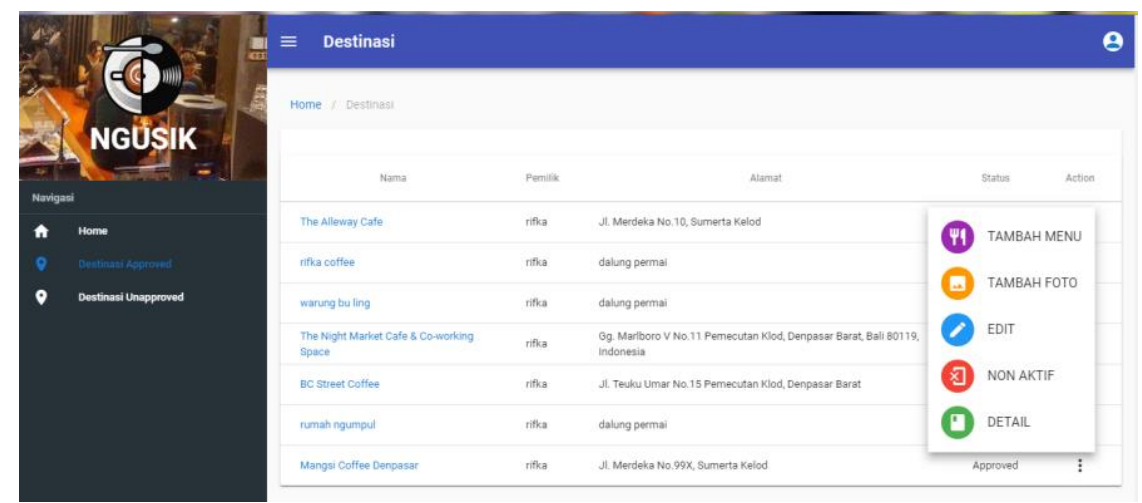

Gambar 9. Menu Destinasi Approved

Halaman admin destinasi juga memiliki menu destinasi unapproved. Tampilan halaman destinasi unapproved dapat dilihat seperti pada Gambar 10.

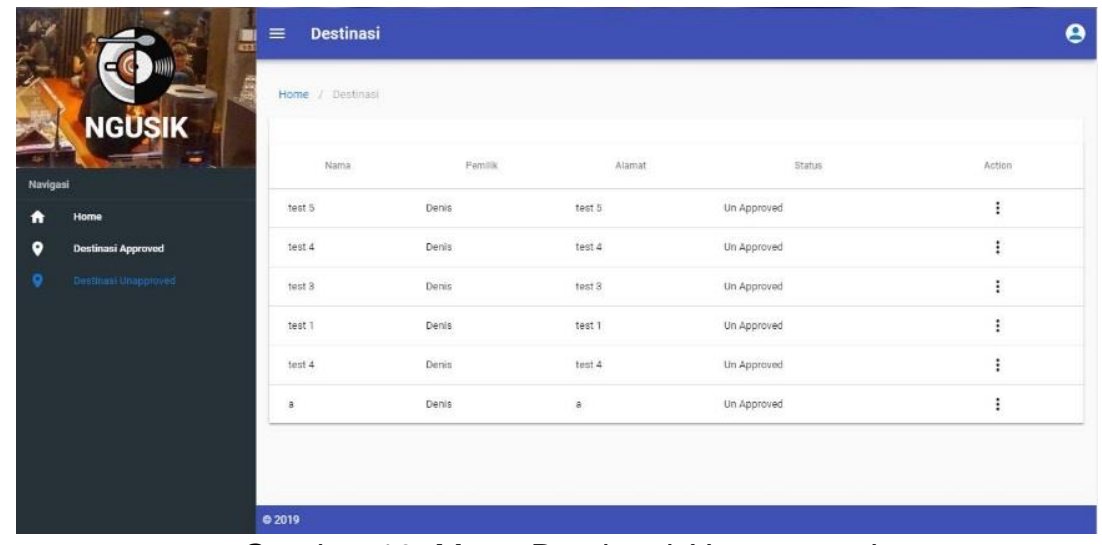

Gambar 10. Menu Destinasi Unapproved 
Admin destinasi dapat melakukan penambahan destinasi melalui platform Android. Tampilan halaman tambah destinasi dapat dilihat seperti pada Gambar 11.

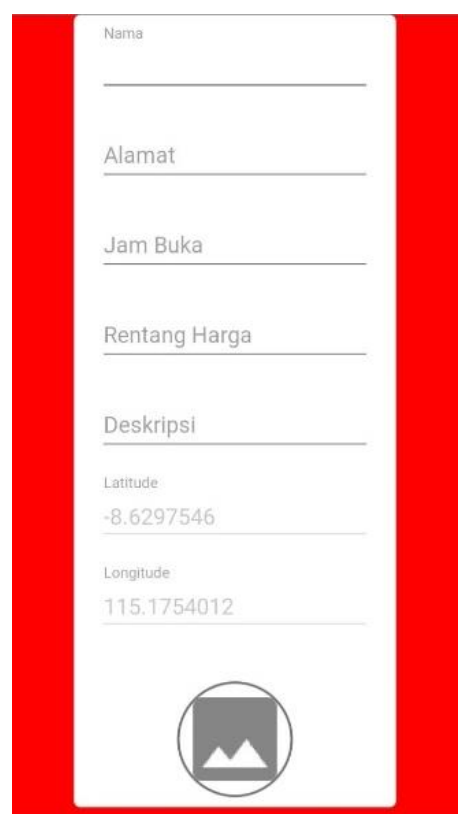

Gambar 11. Halaman Tambah Destinasi

Halaman tambah destinasi merupakan halaman untuk mendaftarkan destinasi baru yang dimiliki admin destinasi. Halaman tambah destinasi meminta admin destinasi untuk mengisi data dari destinasi yang didaftarkan, seperti nama destinasi, alamat, jam buka, deskripsi, dan foto destinasi. Lokasi destinasi pada map diambil secara otomatis berdasarkan posisi GPS dari perangkat genggam admin destinasi pada saat mendaftarkan destinasinya.

\subsubsection{Tampilan Sistem Admin Sistem}

Tampilan sistem admin sistem merupakan tampilan sistem yang digunakan oleh admin sistem pada platform Web. Tampilan pada sistem admin sistem terdiri dari tampilan halaman untuk login, tampilan halaman utama, tampilan halaman dari pemilik, tampilan halaman destinasi approved, tampilan halaman destinasi unapproved, dan tampilan blacklist. Admin sistem harus melakukan login untuk mengakses halaman utaman admin sistem. Tampilan dari halaman login ditunjukan oleh Gambar 12.

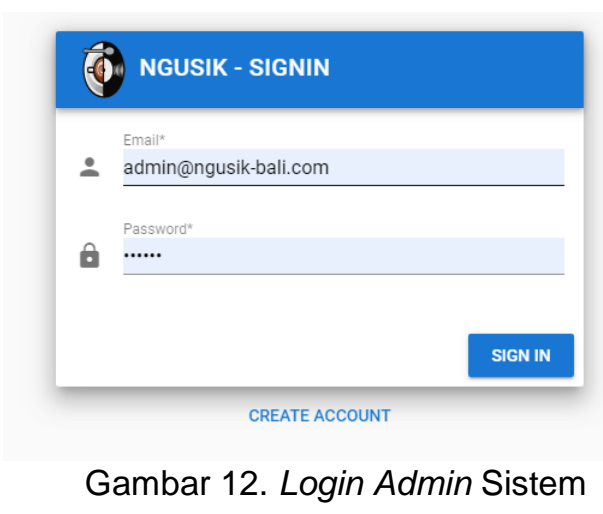

Admin diminta untuk melakukan login terlebih dahulu untuk dapat mengakses halaman utama admin sistem. Tampilan dari halaman utama admin sistem dapat dilihat seperti yang ditunjukan Gambar 13. 


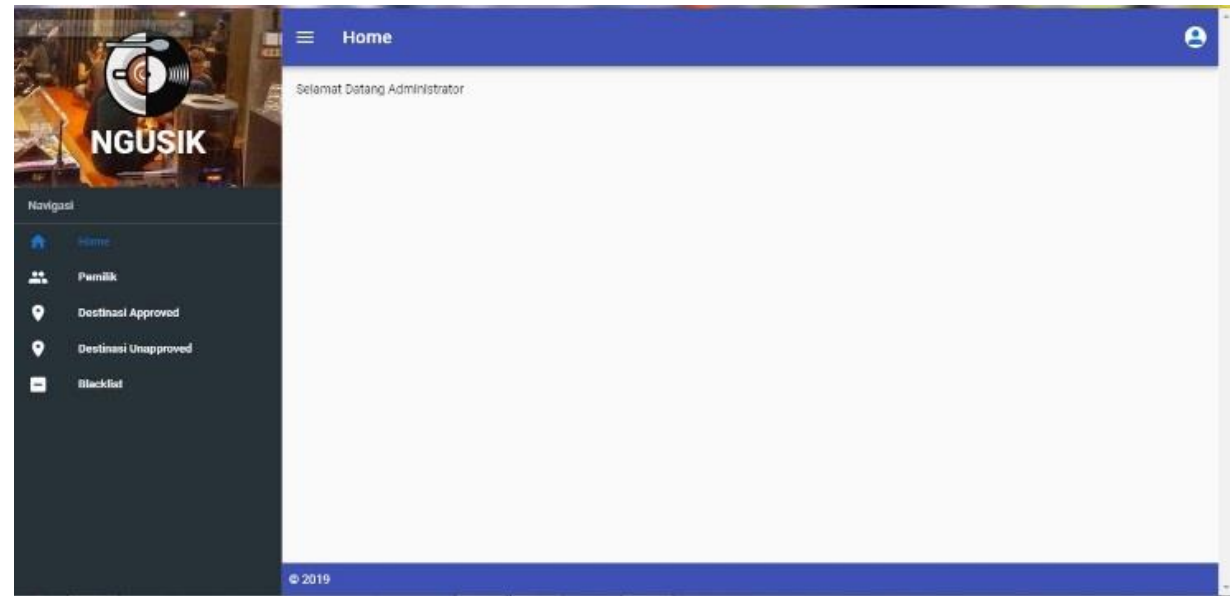

Gambar 13. Halaman Utama Admin Sistem

Admin sistem memiliki otoritas penuh terhadap sistem. Menu yang terdapat pada halaman admin sistem antara lain menu pemilik, menu destinasi approved dan destinasi unapproved. Tampilan menu pemilik dapat dilihat seperti pada Gambar 14.

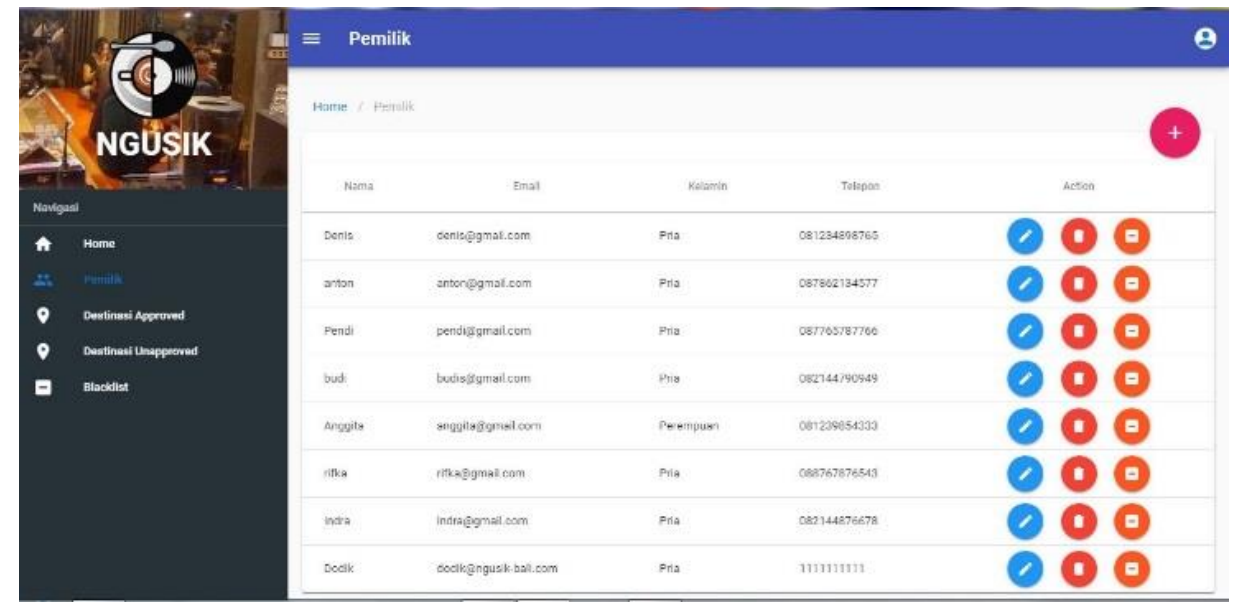

Gambar 14. Halaman Menu Pemilik

\subsection{Analisis Sistem}

Dasar dilakukan analisis sistem agar mengetahui apakah aplikasi NguSik berfungsi sesuai tujuan pengembangan aplikasi. Analisis dilakukan terhadap platform Web dan Android pada kondisi dan spesifikasi yang berbeda. Analisis sistem NguSik menghasilkan berupa dua output, yaitu kelebihan serta kekurangan. Kelebihan sistem informasi geografis destinasi ngumpul asik "NguSik" berbasis platform Android adalah sebagai berikut:

1. Sistem informasi geografis destinasi ngumpul asik "NguSik" berbasis platform Android dapat memberikan informasi rinci terhadap destinasi yang dapat diakses dimana saja dan kapan saja karena dibangun diatas platform Android.

2. Sistem informasi geografis destinasi ngumpul asik "NguSik" berbasis platform Android mampu menghasilkan tampilan yang user friendly sehingga dapat digunakan dengan mudah oleh pengguna.

Penerapan sistem informasi geografis destinasi ngumpul asik "NguSik" berbasis platform Android memiliki kekurangan sebagai berikut:

1. Sistem informasi geografis destinasi ngumpul asik "NguSik" berbasis platform Android belum memiliki fitur pencarian destinasi yang terdaftar. 
2. Sistem informasi geografis destinasi ngumpul asik "NguSik" berbasis platform Android belum dapat melakukan check in otomatis.

\section{Kesimpulan}

Penyebaran kuesioner digunakan untuk memperoleh hasil pengujian yang terdiri dari 22 pertanyaan yang dibagi menjadi 4 kategori yaitu desain, warna, fungsionalitas, dan kemudahan kepada responden. Hasil yang didapat berupa nilai yang didominasi dengan sangat setuju dan setuju. Kategori desain mendapat penilaian dengan hasil sangat setuju sebanyak $64 \%$ dan setuju yaitu sebanyak $36 \%$, kategori warna mendapat penilaian dengan hasil sangat setuju sebanyak $64 \%$, setuju yaitu sebanyak $28 \%$, dan cukup sebanyak $8 \%$, kategori fungsionalitas mendapat penilaian dengan hasil sangat setuju sebanyak $90 \%$ dan setuju yaitu sebanyak $10 \%$, serta kategori kemudahan dalam penggunaan aplikasi mendapat penilaian dengan hasil sangat setuju sebanyak $72 \%$ dan setuju yaitu sebanyak $28 \%$. Hasil yang didapat memperlihatkan ratarata persentase tertinggi pada kategori sangat setuju, sehingga dapat disimpulkan bahwa aplikasi sistem informasi geografis destinasi ngumpul asik "NguSik" berbasis platform Android dapat memberikan informasi yang rinci mengenai destinasi ngumpul yang ada kepada para pengguna.

\section{Daftar Pustaka}

[1] A. Fauzi, I. N. Punia, dan G. Kamajaya, "Tinjauan Gaya Hidup Anak Muda di Kota Denpasar," Jurnal Ilmiah Sosiologi, vol. 1, no. 1, 2017.

[2] I. Widnyana, I. Piarsa, dan A. Agung Cahyawan W., "Aplikasi Sistem Informasi Geografis Bengkel di Kota Denpasar Berbasis Android," Jurnal Ilmiah Merpati, vol. 3, no. 1, hal. 23-30, 2016.

[3] M. Y. P. Mahendra, I. N. Piarsa, dan D. Putra Githa, "Geographic Information System of Public Complaint Testing Based on Mobile Web (Public Complaint)," Lontar Komputer Jurnal IImiah Teknologi Informasi, vol. 9, no. 2, hal. 95, 2018.

[4] S. Alfeno dan R. E. C. Devi, "Implementasi Global Positioning System (GPS) dan Location Based Service (LSB) pada Sistem Informasi Kereta Api untuk Wilayah Jabodetabek," Sisfotek Global, vol. 7, no. 2, hal. 27-33, 2017.

[5] L. G. Sri Handayani, I. N. Piarsa, dan K. Suar Wibawa, "Sistem Informasi Geografis Pemetaan Jalan Desa Berbasis Web," Lontar Komputer Jurnal IImiah Teknologi Informasi, vol. 6, no. 2, hal. 128, 2015.

[6] A. Rahmi, N. Piarsa, dan P. Wira Buana, "FinDoctor-Interactive Android Clinic Geographical Information System Using Firebase and Google Maps API," International Journal New Technology Research, no. 3, hal. 8-12, 2017.

[7] I. N. Piarsa, E. S. Hadi, N. Kadek, dan A. Wirdiani, "Rural Road Mapping Geographic Information System Using Mobile Android," IJCSI International Journal Computer Science Issues, vol. 12, no. 3, hal. 95-100, 2015.

[8] B. Yuwono, A. S. Aribowo, dan F. A. Setyawan, "Sistem Informasi Geografis Berbasis Android untuk Pariwisata di Daerah Magelang," Jurnal IImiah Teknik Informasi, vol. 2015, no. 2015, hal. 68-74, 2015.

[9] I. W. W. Gautama, I. K. G. D. Putra, dan I. M. Sukarsa, "Aplikasi Pemetaan Objek Wisata Pantai Bali Selatan Berbasis Android," Jurnal Ilmiah Merpati, vol. 4, no. 1, hal. 43-51, 2016.

[10] E. Maiyana, "Pemanfaatan Android Dalam Perancangan Aplikasi Kumpulan Doa," Jurnal Sains dan Informatika, vol. 4, no. 1, hal. 54-65, 2018. 